\title{
Multilevel level single phase inverter implementation for reduced harmonic contents
}

\author{
Taha A. Hussein \\ Department of Electrical Power Techniques Engineering, Engineering Technical College, Northern Technical University \\ Mosul, Iraq
}

\begin{tabular}{|c|c|}
\hline Article Info & ABSTRACT \\
\hline & \multirow{9}{*}{$\begin{array}{l}\text { Selective harmonic elimination technique SHE is adopted in this work to } \\
\text { reduce the harmonic contents in single phase cascaded multilevel inverter. } \\
\text { The firing instants for the electronic switches MOSFETs in the inverter are } \\
\text { calculated off line for five level to thirteen level inverter. An Arduino } \\
\text { microcontroller is programmed to cope with different topologies of the } \\
\text { multilevel inverter. The implemented multi-level (MLI) inverter results are } \\
\text { compared with Simulink simulation program and are found very close to } \\
\text { each other. SHE technique works at system frequency ( } 50 \mathrm{~Hz} \text { or } 60 \mathrm{~Hz} \text { ) and } \\
\text { the switching losses are very small. The sinusoidal pulse width modulation } \\
\text { SPWM requires a carrier frequency not less } 20 \text { times the system frequency so } \\
\text { SHE approach is found to be superior compared with SPWM. Also, SHE } \\
\text { technique shows significant reduction in THD as the number of levels } \\
\text { increased. Results for the output voltages and currents along with their } \\
\text { frequency spectrum are shown and compared with traditional SPWM. }\end{array}$} \\
\hline Received Aug 28, 2020 & \\
\hline Revised Jan 14, 2021 & \\
\hline Accepted Feb 3, 2021 & \\
\hline Keywords: & \\
\hline Arduino & \\
\hline MLI & \\
\hline SHE & \\
\hline SPWM & \\
\hline
\end{tabular}

This is an open access article under the CC BY-SA license.

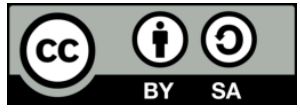

\section{Corresponding Author:}

Taha A. Hussein

Department of Electrical power techniques engineering

Engineering Technical College, Northern Technical University, Mosul, Iraq

Email: taha_hussian@yahoo.com

\section{INTRODUCTION}

Multilevel inverters consist of cascaded stages of single-phase inverters. They are used for high power conversion from DC to AC. They found wide range of applications in transport, electric vehicles, renewable energy and many other applications [1]. Multilevel inverters have two distinct features. First, they operate at system frequency (low order $50 \mathrm{~Hz}$ or $60 \mathrm{~Hz}$ ) which means very low switching losses. Second the output voltage has very low total harmonic distortion due to the multi stair shape in the output. The cascaded multilevel inverters CMLI is designed by using H-bridges in series and its arrangement is simple, the most attractive of this topology in the medium to high voltage $(2-13 \mathrm{Kv})$ [2]. ther types of inverter like Neutral point clamped (NPC) inverters and flying capacitor (FC) inverters. Main disadvantage of CMLI configuration is the increase number of switching devices and its complex driver circuit [3]. By developing new topology of inverters, the complexity can be reduced and hence the reliability can be increased. By having inverters with a smaller number of switches, for the similar voltage level the reliability of the inverters can be improved [4]. Most recently the CML inverters are used in the field of renewable energy [5]. Recent development of CML includes low switching frequency based asymmetrical multilevel inverter topology with reduced switch count [6] and A new multilevel inverter topology with reduce switch count [7]. In this work CML with two, three and four H-bridges four controlled by Arduino microcontroller is implemented. A Simulink model for selective harmonic elimination is built through Matlab and the results are compared with the practical ones. Then these results are compared with the traditional sinusoidal pulse modulation technique 
to verify the validity of the proposed model. The control of the inverter output voltage is important for many aspects like the variation of the input dc voltage, to get a regulated output voltage and to keep the voltage to frequency ratio at constant mode [6]. The inverter gain can be controlled in different techniques employing PWM control as the basic building block. The sinusoidal PWM is commonly used where a sinusoidal reference signal with a frequency $\mathrm{f}_{\mathrm{r}}$ is compared with a triangular carrier wave of frequency $\mathrm{f}_{\mathrm{c}}$. In this method $f_{c}$ is in kilohertz range compared with low frequency $f_{r}$ i.e. $50 \mathrm{~Hz}$ or $60 \mathrm{~Hz}$. The MOSFEs, which are commonly used as electronic switches in the inverter topology, must be chosen to cope with the carrier frequency, which results in significant high-power loss. The alternative method is to use selective harmonic elimination method SHE where the inverter works only on the reference signal frequency $f_{r}$. The instantaneous output voltage of the inverter is a square wave with $\mathrm{f}_{\mathrm{r}}$ frequency (i.e. $50 \mathrm{~Hz}$ or $60 \mathrm{~Hz}$ ). This voltage can be expressed in Fourier series as

$$
\mathrm{v}_{\mathrm{o}}=\frac{\mathrm{a}_{\mathrm{o}}}{2}+\sum_{\mathrm{n}=1}^{\infty}\left(\mathrm{a}_{\mathrm{n}} \cos (\mathrm{nwt})+\mathrm{b}_{\mathrm{n}} \sin (\mathrm{nwt})\right)
$$

Due to quarter wave symmetry along the $\mathrm{x}$-axis, both $\mathrm{a}_{\mathrm{o}}$ and $\mathrm{a}_{\mathrm{n}}$ are zero. We get

$$
b_{n}=\frac{1}{\pi}\left[\int_{\frac{-\pi}{2}}^{0} \frac{-v_{s}}{2} \sin (n w t) d(w t)+\int_{0}^{\frac{\pi}{2}} \frac{v_{s}}{2} \sin (n w t) d(w t)\right]=\frac{2 v_{s}}{n \pi}
$$

Which gives the instantaneous output voltage

$$
\begin{aligned}
\mathrm{v}_{\mathrm{o}} & =\sum_{\mathrm{n}=1,3,5, \ldots .} \frac{2 \mathrm{v}_{\mathrm{s}}}{\mathrm{n} \pi} \sin (\mathrm{nwt}) \\
& =0 \text { for } \mathrm{n}=2,4,6
\end{aligned}
$$

For the unipolar output voltage notches the coefficient $b_{n}$ is given by

$$
b_{n=} \frac{4 V_{s}}{\pi}\left[\int_{0}^{\alpha_{1}} \sin (n w t) d(w t)+\int_{\alpha_{2}}^{\frac{\pi}{2}} \sin (n w t) d(w t)\right]=\frac{4 V_{s}}{\pi} \frac{1-\cos n \alpha_{1}+\cos n \alpha_{2}}{n}
$$

In (4) can be extended to m notches per quarter wave (quasi-square symmetry) as,

$$
\mathrm{b}_{\mathrm{n}}=\frac{4 \mathrm{~V}_{\mathrm{s}}}{\mathrm{n} \pi}\left[1+\sum_{\mathrm{k}=1}^{\mathrm{m}}(-1)^{\mathrm{k}} \cos \left(\mathrm{n} \alpha_{\mathrm{k}}\right)\right] \text { for } \mathrm{n}=1,3,5 \text {, }
$$

where $\alpha_{1}<\alpha_{2}<\cdots . . \alpha_{\mathrm{k}}<\frac{\pi}{2}$

This method works efficiently for any number of harmonics to be eliminated and adopted throughout this work. Multilevel inverters include an array of power semiconductor switches especially MOSFET's and a combination of DC sources, the output of multilevel inverter is stepped waveforms of theses DC sources. If we let $\mathrm{s}$ as the number of steps of the phase voltage with reference to the negative terminal of the inverter, then the number of steps in the voltage between the two phases of the load $\mathrm{k}$ is $\mathrm{k}=2 \mathrm{~s}+1$. The total harmonic distortion (THD) can be reduced significantly if we increase the number of levels in the inverter. The efficient control methods for multilevel inverters may include sinusoidal pulse width modulation (SPWM), space vector pulse width modulation (SVPWM) and selective harmonic elimination [7].

\section{SELECTIVE HARMONIC ELIMINATION}

In this technique, numbers of harmonics to be eliminated is to be defined. For instance, a sevenlevel inverter, we have three full bridge inverter then the $3 \mathrm{rd}$, 5th harmonics are to be eliminated. An off-line determination for the switching instants of the multilevel inverter is shown in Figure 1. After locating $\alpha_{1}, \alpha_{2}$ and $\alpha_{3}$ on the Figure a mirror image is drawn around $\pi / 2$, this is what we need for the positive cycle of the inverter output. Then the process is repeated for the negative output cycle. These instants are fed to the MOSFET switches according to each level and the expected output voltage is shown in Figure 2. Table 1 and Figure 3 summarizes the MOSFET switches state, the period of operation and the level of the output voltage for a seven level MLI. The following nonlinear equations has to be solved in order to find the values for the triggering angles $\alpha_{1}, \alpha_{2}$ and $\alpha_{3}$.

$$
1-\cos \alpha_{1}+\cos \alpha_{2}-\cos \alpha_{3}=\frac{4 V_{s}}{\pi}
$$


$1-\cos 3 \alpha_{1}+\cos 3 \alpha_{2}-\cos 3 \alpha_{3}=0$

$1-\cos 5 \alpha_{1}+\cos 5 \alpha_{2}-\cos 5 \alpha_{3}=0$

A Newton Raphson method is used as a common numerical solver for nonlinear solution, which determines the values to be: $\alpha_{1}=13.22^{\circ}, \alpha_{2}=38^{\circ}$ and $\alpha_{3}=82.9^{\circ}$.

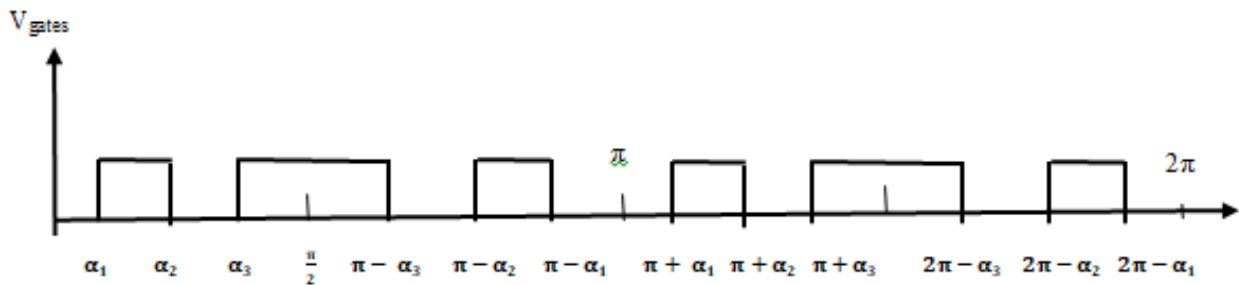

Figure 1. Determination of triggering instants using quarter wave symmetry

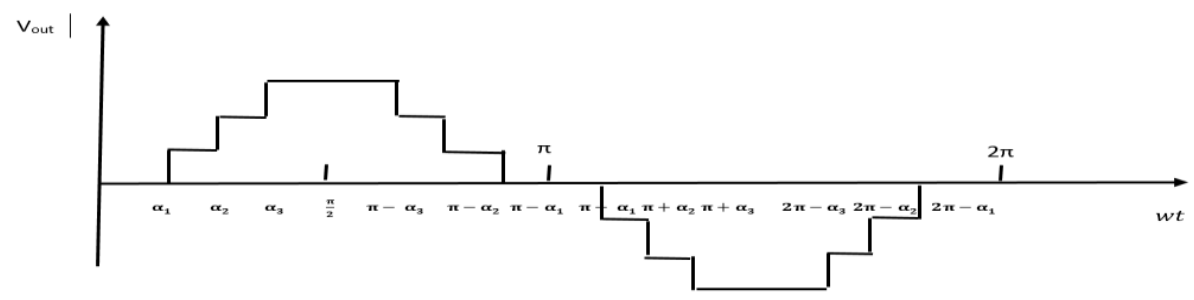

Figure 2. The expected output voltage for Figure 1

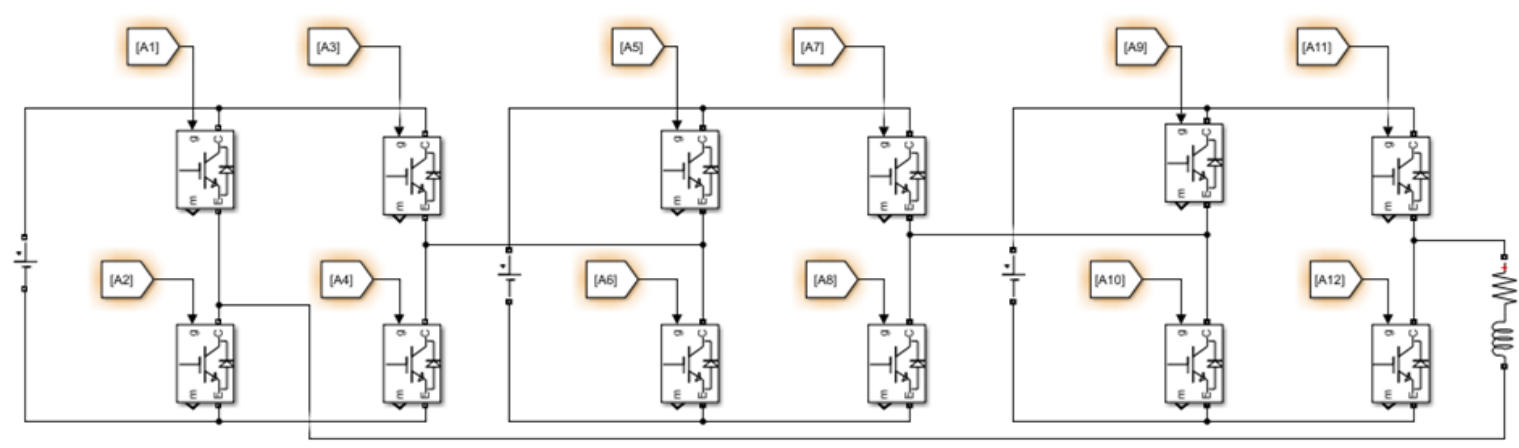

Figure 3. Seven level inverter

Table 1. Determination of triggering instants for seven level MLI inverter

\begin{tabular}{cccccccccccccc}
\hline S1 & S2 & S3 & S4 & S5 & S6 & S7 & S8 & S9 & S10 & S11 & S12 & Period & DC level \\
\hline 1 & 0 & 1 & 0 & 1 & 0 & 1 & 0 & 1 & 0 & 1 & 0 & $\alpha_{1}$ & 0 \\
1 & 1 & 0 & 0 & 1 & 0 & 1 & 0 & 1 & 0 & 1 & 0 & $\alpha_{2}-\alpha_{1}$ & $+\mathrm{V}_{\mathrm{DC}}$ \\
1 & 1 & 0 & 0 & 1 & 1 & 0 & 0 & 1 & 0 & 1 & 0 & $\alpha_{3}-\alpha_{2}$ & $+2 \mathrm{~V}_{\mathrm{DC}}$ \\
1 & 1 & 0 & 0 & 1 & 1 & 0 & 0 & 1 & 1 & 0 & 0 & $\pi-2 \alpha_{3}$ & $+3 \mathrm{~V}_{\mathrm{DC}}$ \\
1 & 1 & 0 & 0 & 1 & 1 & 0 & 0 & 0 & 1 & 0 & 1 & $\alpha_{3}-\alpha_{2}$ & $+2 \mathrm{~V}_{\mathrm{DC}}$ \\
1 & 1 & 0 & 0 & 0 & 1 & 0 & 1 & 0 & 1 & 0 & 1 & $\alpha_{2}-\alpha_{1}$ & $+\mathrm{V}_{\mathrm{DC}}$ \\
0 & 1 & 0 & 1 & 0 & 1 & 0 & 1 & 0 & 1 & 0 & 1 & $2 \alpha_{1}$ & 0 \\
0 & 0 & 1 & 1 & 0 & 1 & 0 & 1 & 0 & 1 & 0 & 1 & $\alpha_{2}-\alpha_{1}$ & $-\mathrm{V}_{\mathrm{DC}}$ \\
0 & 0 & 1 & 1 & 0 & 0 & 1 & 1 & 0 & 1 & 0 & 1 & $\alpha_{3}-\alpha_{2}$ & $-2 \mathrm{~V}_{\mathrm{DC}}$ \\
0 & 0 & 1 & 1 & 0 & 0 & 1 & 1 & 0 & 0 & 1 & 1 & $\pi-2 \alpha_{3}$ & $-3 \mathrm{~V}_{\mathrm{DC}}$ \\
0 & 0 & 1 & 1 & 0 & 0 & 1 & 1 & 1 & 0 & 1 & 0 & $\alpha_{3}-\alpha_{2}$ & $-2 \mathrm{~V}_{\mathrm{DC}}$ \\
0 & 0 & 1 & 1 & 1 & 0 & 1 & 0 & 1 & 0 & 1 & 0 & $\alpha_{2}-\alpha_{1}$ & $-\mathrm{V}_{\mathrm{DC}}$ \\
1 & 0 & 1 & 0 & 1 & 0 & 1 & 0 & 1 & 0 & 1 & 0 & $\alpha_{1}$ & 0 \\
\hline
\end{tabular}




\section{IMPLEMENTATION OF MULTILEVEL SINGLE-PHASE INVERTER}

Ersoy Beser presents a single-phase multilevel inverter for using as a voltage harmonic source. The switching signals are determined by a PIC18F45 microcomputer [8]. Tapan Kumar addresses the simulation and practical implementation of a single -phase multilevel inverters consisting of three $\mathrm{H}$-bridge units to generate a maximum of 14 level output voltage. the set signals for MOSFETs are generated by using ATmega 2560 micro controller-based Arduino board [9]. Pouya Tarassadi paper introduces a SPWM cascaded full bridge single phase 7-level inverter with optimized shift modulation [10]. In this work implementation of cascaded multilevel inverter for variety of unlimited levels. The triggering instants are generated by ATmega 2560. The strategy of triggering angles is based on selective harmonic elimination. In this case the operating frequency is the system frequency i.e. $50 \mathrm{~Hz}$ or $60 \mathrm{~Hz}$. No need for any high carrier frequency as the case in SPWM. Then a Simulink model is built, and results are compared with practical ones for validation. A prototype model for cascaded multilevel inverter consists of power section of four single phase inverter that is 16 MOSFETs for switching purpose. The controller is Arduino Mega 2560 with 16 digital output signals. Four optocouplers are used to isolate the controller and the power circuit from any abnormal working conditions. For any level of the cascaded MLI associated off line program is uploaded to the controller and the related triggering instants are fed to the MOSFETs. The practical results are compared with a Simulink model built for this purpose. Generation of any multilevel output voltage from single-phase multilevel inverter consisting of cascaded three H-bridge units [11]-[17]. A New multilevel level singlephase inverter employing vector control gives better utilization of dc power supply and reduced harmonic distortion [18-20]. Adopting Low switching frequency control reduces power losses and enhancing the THD factor in the multilevel cascaded $\mathrm{H}$ bridge inverters [21]-[27].

\section{RESULTS}

Two cascaded single-phase $\mathrm{H}$ bridge inverter are connected to get five level inverter. Two nonlinear equations are solved using Newton Raphson method and the triggering angles are determined to be $\alpha_{1}=$ $5.07^{\circ}$ and $\alpha_{2}=54.9^{\circ}$. Figure 4(a) shows the output voltage for five level inverter with two de power supply $10 \mathrm{~V}$ each $(\max$ output $=20 \mathrm{~V})$ and for modulation index $\mathrm{m}=1$. The output current for the five-level inverter with inductive load with $R=5 \Omega$ and $L=5 \mathrm{mH}$ is shown in Figure 4(b). The frequency spectrum shows the absence of the $3^{\text {rd }}$. The $5^{\text {th }}$ harmonics is present at $250 \mathrm{~Hz}$ followed by the $7^{\text {th }}$ harmonics at $350 \mathrm{~Hz}$. The current starts a new value according to the triggering instants. Here we have two distinct change of current as we have two triggering instants.

$$
\begin{aligned}
& 1-\cos \alpha_{1}+\cos \alpha_{2}=\frac{4 \mathrm{~V}_{s}}{\pi} \\
& 1-\cos 3 \alpha_{1}+\cos 3 \alpha_{2}=0
\end{aligned}
$$

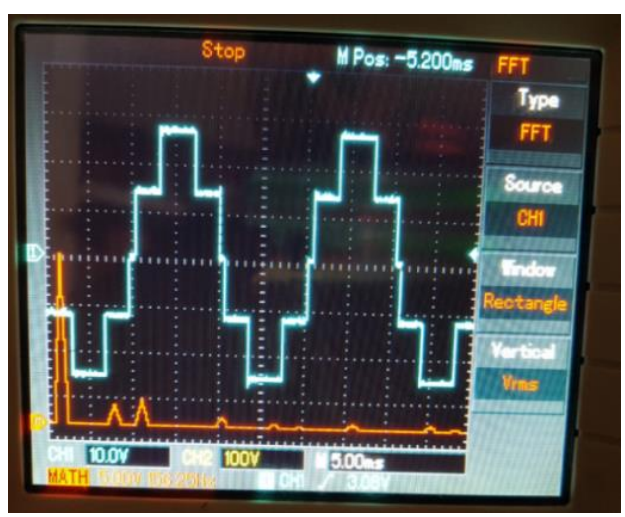

(a)

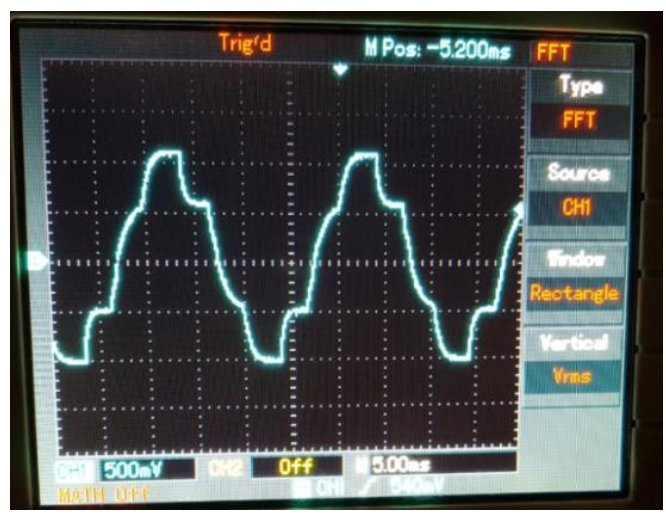

(b)

Figure 4. (a) five level inverter shows the output voltage and frequency spectrum $156.25 \mathrm{~Hz} / \mathrm{div}$, (b) output current

For a seven-level inverter (with three dc power supply $10 \mathrm{~V}$ each , max output=30V) and for modulation index $\mathrm{m}=1$ There are seven different values of output voltage, manly $0 \mathrm{Volt},+\mathrm{V}_{\mathrm{DC}},+2 \mathrm{~V}_{\mathrm{DC}}$, 
$+3 V_{D C},-V_{D C},-2 V_{D C}$ and $-3 V_{D C}$, where $V_{D C}$ is the DC input to the inverter. Here we have three nonlinear equations to be solved.

$$
\begin{aligned}
& 1-\cos \alpha_{1}+\cos \alpha_{2}-\cos \alpha_{3}=\frac{4 \mathrm{~V}_{\mathrm{s}}}{\pi} \\
& 1-\cos 3 \alpha_{1}+\cos 3 \alpha_{2}-\cos 3 \alpha_{3}=0 \\
& 1-\cos 5 \alpha_{1}+\cos 5 \alpha_{2}-\cos 5 \alpha_{3}=0
\end{aligned}
$$

The values of the triggering angles are found to be $\alpha_{1}=13.22^{\circ}, \alpha_{2}=38^{\circ}$ and $\alpha_{3}=82.9^{\circ}$.

The output voltage along with its frequncy spctrum is shown in Figure 5(a). The frequency spectrum shows the absence of the $3^{\text {rd }}$ and $5^{\text {th }}$ harmonics. The $7^{\text {th }}$ harmonic is present at frequency $=350 \mathrm{~Hz}$. Here we have three different instants of triggering and so we have three different changes in the current values as shown in Figure 5(b). This makes the current approaches more sinusoidal shape, which in turns reduces the total harmonic distortion THD.

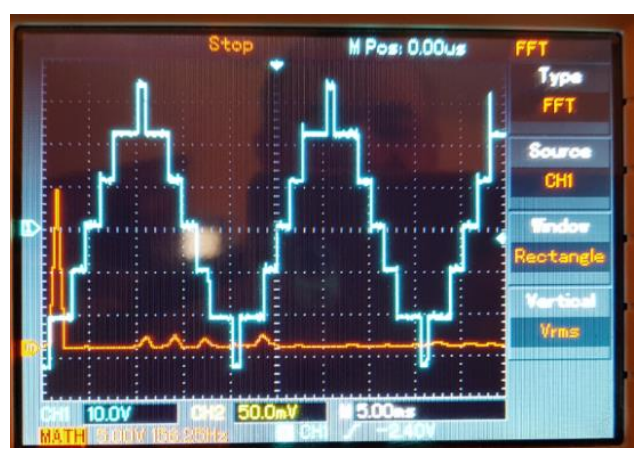

(a)

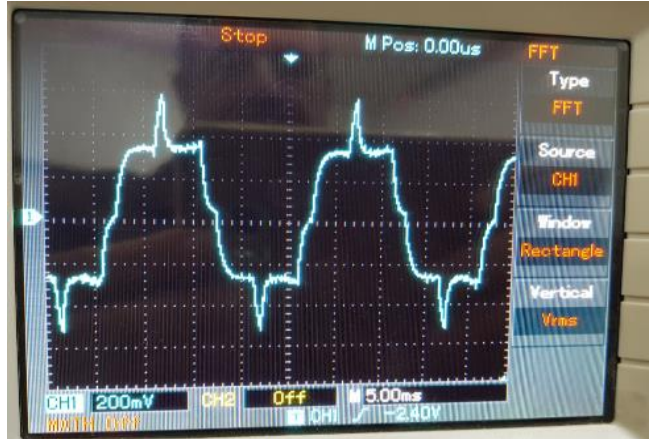

(b)

Figure 5. Seven level inverter (a) output voltage and frequency spectrum $156.25 \mathrm{~Hz} / \mathrm{div}$ (b) output current

As we increase number of inverter levels more odd harmonics is eliminated and the shape of the out current approaches more sinusoidal shapes. This is clear in the nine-level inverter shown in Figure 6(a) where the $3^{\text {rd }}, 5^{\text {th }}$ and $7^{\text {th }}$ harmonics are eliminated. Frequency spectrum shows the presence of the $9^{\text {th }}$ harmonic at frequency $=450 \mathrm{~Hz}$. The output current is shown in Figure 6(b). Here we have five nonlinear equations to be solved

$$
\begin{aligned}
& 1-\cos \alpha_{1}+\cos \alpha_{2}-\cos \alpha_{3}+\cos \alpha_{4}=\frac{4 \mathrm{~V}_{s}}{\pi} \\
& 1-\cos 3 \alpha_{1}+\cos 3 \alpha_{2}-\cos 3 \alpha_{3}+\cos 3 \alpha_{4}=0 \\
& 1-\cos 5 \alpha_{1}+\cos 5 \alpha_{2}-\cos 5 \alpha_{3}+\cos 5 \alpha_{4}=0 \\
& 1-\cos 7 \alpha_{1}+\cos 5 \alpha_{2}-\cos 7 \alpha_{3}+\cos 7 \alpha_{4}=0
\end{aligned}
$$

And the corresponding solution gives $\alpha_{1}=5.25^{\circ}, \alpha_{2}=28.12^{\circ}, \alpha_{3}=46.38^{\circ}$ and $\alpha_{4}=84.09^{\circ}$.

A practical set for multilevel single-phase inverter that is used for different cascaded MLI is shown in Figure 7. As the number of levels is increased the THD is decreased significantly as conclude in Table 2.

A proteus program for a nine level inverter that is uploaded to the ardunio microcontroller and shown in Figure 8(a). A Matlab file for calculating the triggering angles for nine level inverter is shown in Figure 8(b). To ensure quarter wave symmetry $\alpha_{1}<\alpha_{2}<\alpha_{3}<\alpha_{4}<\alpha_{5}<\pi / 2$. In order to work with different values of modulation indexes $(0<m<1)$ an $m$ file is executed and the relation between the modulation index and its corresponding triggering angles is shown in Figure 8(c). 


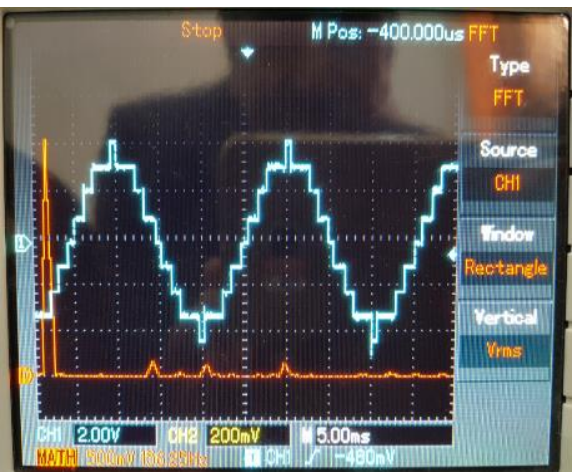

(a)

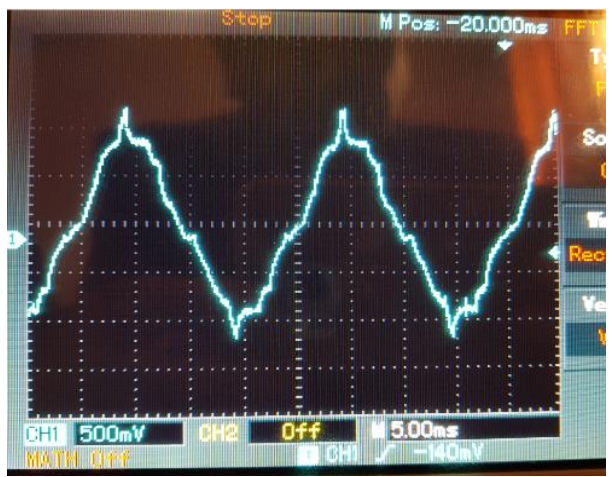

(b)

Figure 6. Nine level inverter (a) voltage and frequency spectrum $156.25 \mathrm{~Hz} / \mathrm{div}$ (b) output current

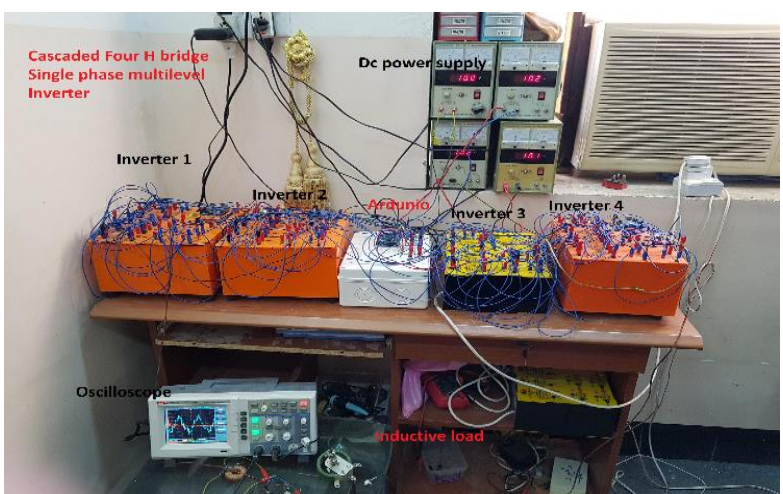

Table 2. THD values for different inverter levels

\begin{tabular}{ccc}
\hline No. of levels & Fundamental & THD \\
\hline five & $20.03 \%$ & $27.03 \%$ \\
Seven & $29.94 \%$ & $17.92 \%$ \\
Nine & $35.88 \%$ & $14.95 \%$ \\
Eleven & $49.9 \%$ & $10.53 \%$ \\
\hline
\end{tabular}

Figure 7. A practical set for MLI

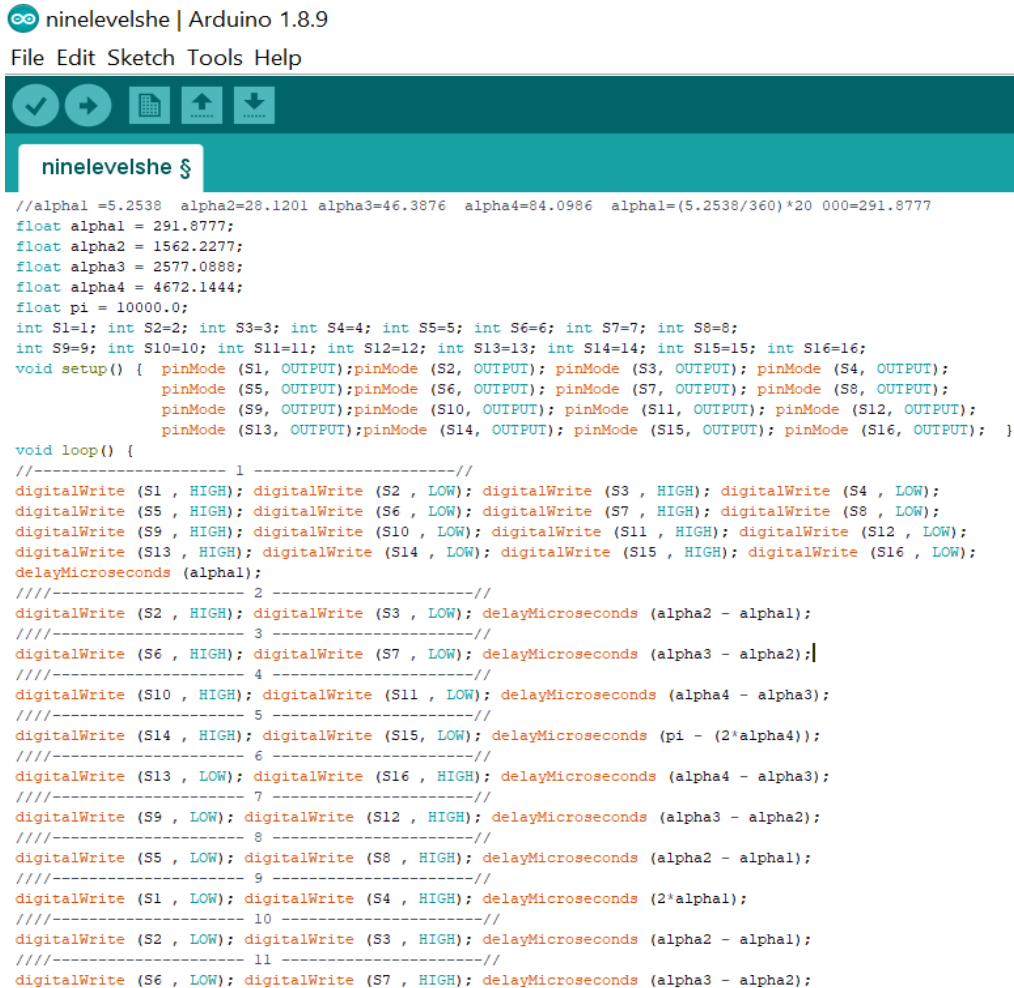

(a) 


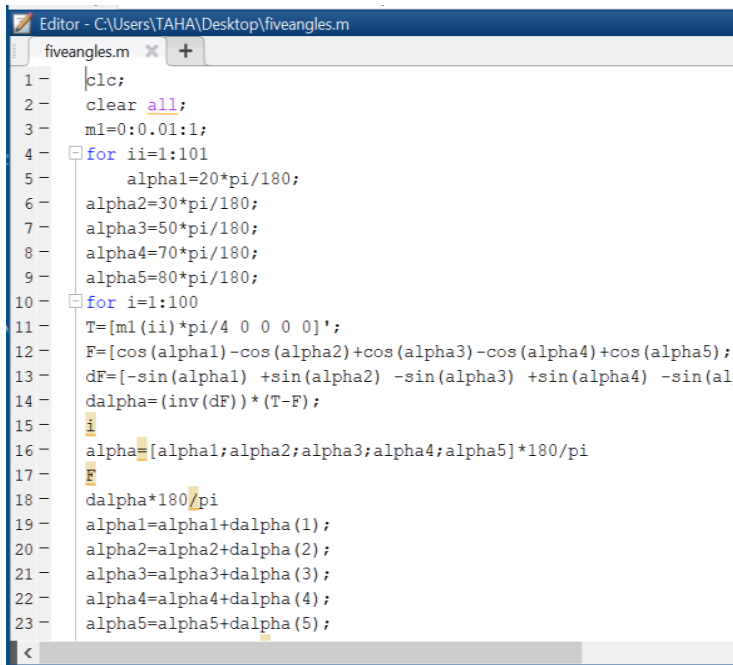

(b)

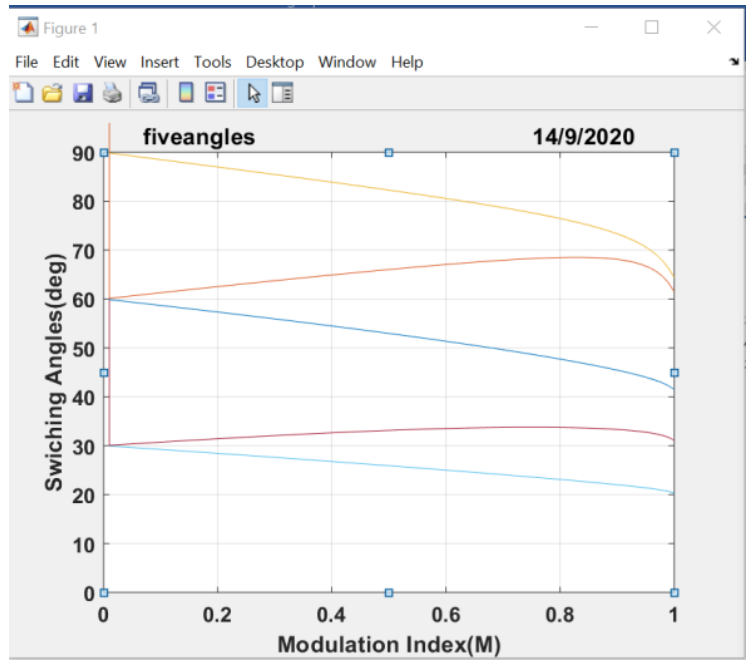

(c)

Figure 8. Illustrating programmes (a) proteus program, (b) M-file Neton Raphson, (c) modulation index range

The Simulink model for nine level MLI using selective harmonic approach (with the same DC supply voltages values that are used in the practical part i.e. 10V/supply is shown in Figure 9. The output voltage shown in Figure 10 shows agreement compared with the practical results shown previously in Figure 6 and the THD value is within the accepted level.
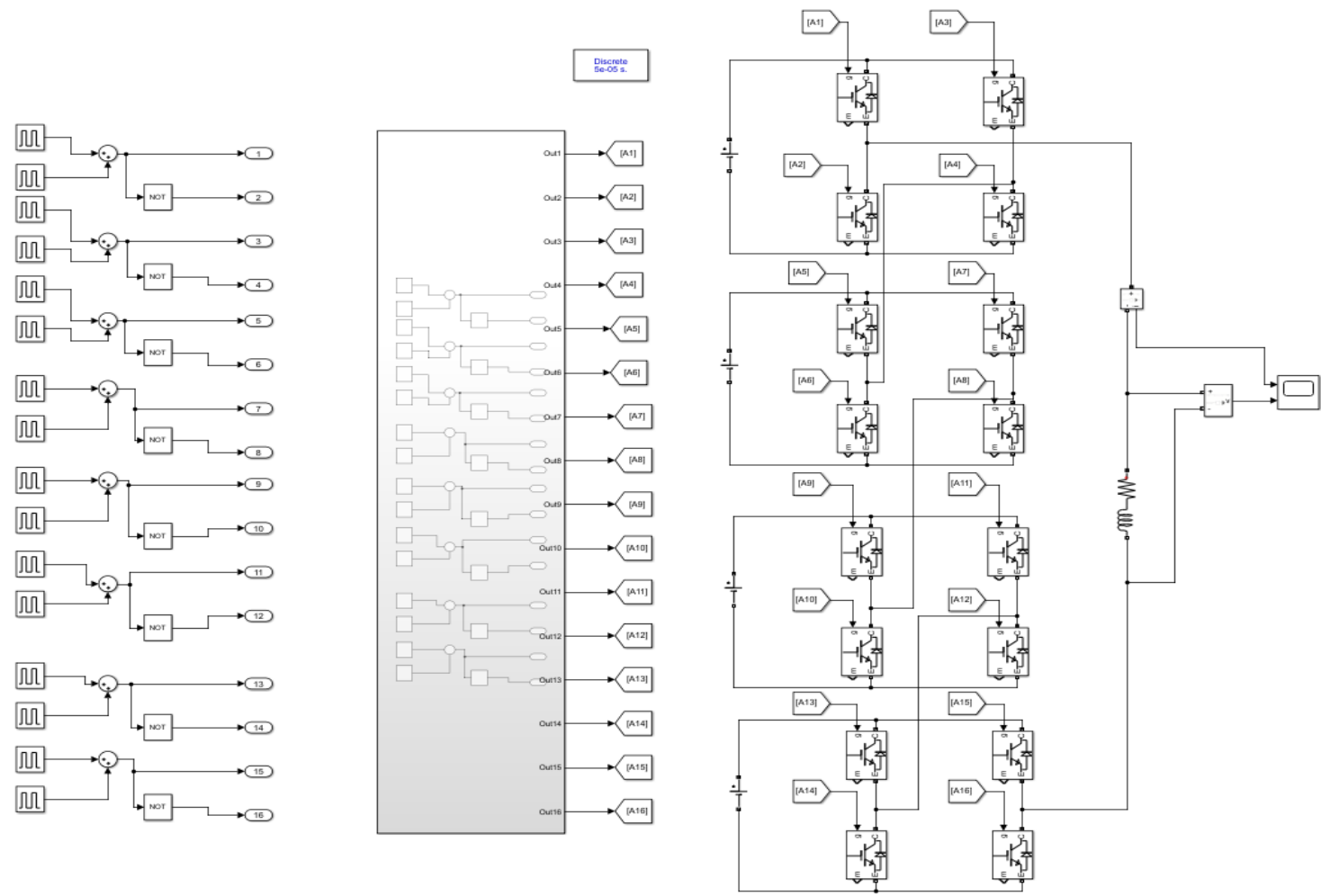

Figure 9. Matlab Simulink model for nine level inverter using SHE 


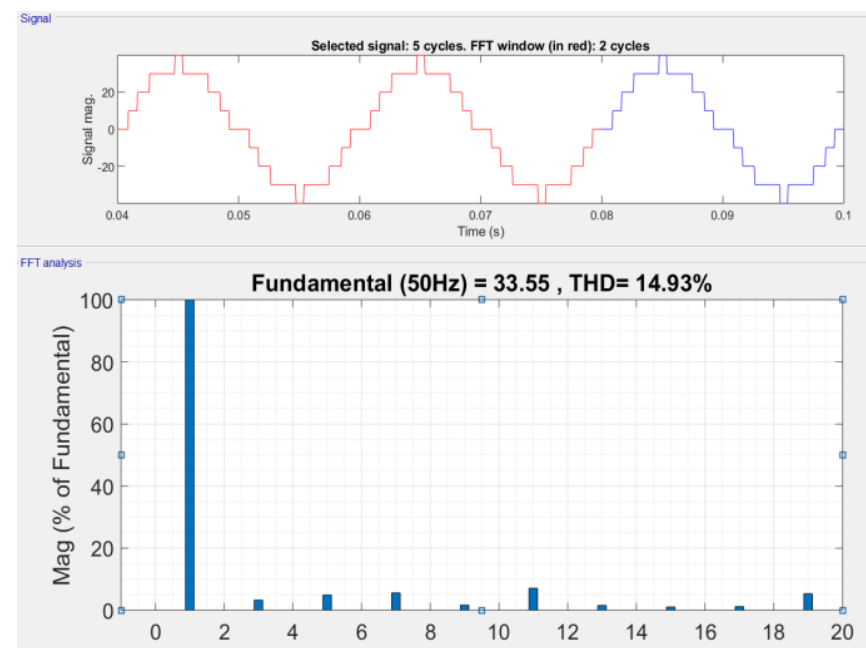

Figure 10. Simulink output voltage and frequency spectrum for nine level inverter using SHE

To compare SHE technique with SPWM a Simulink model for nine level MLI using SPWM approach is shown in Figure 11. A carrier frequency of $f_{c}=1300 \mathrm{~Hz}$ is used for the triangular waveform supply.
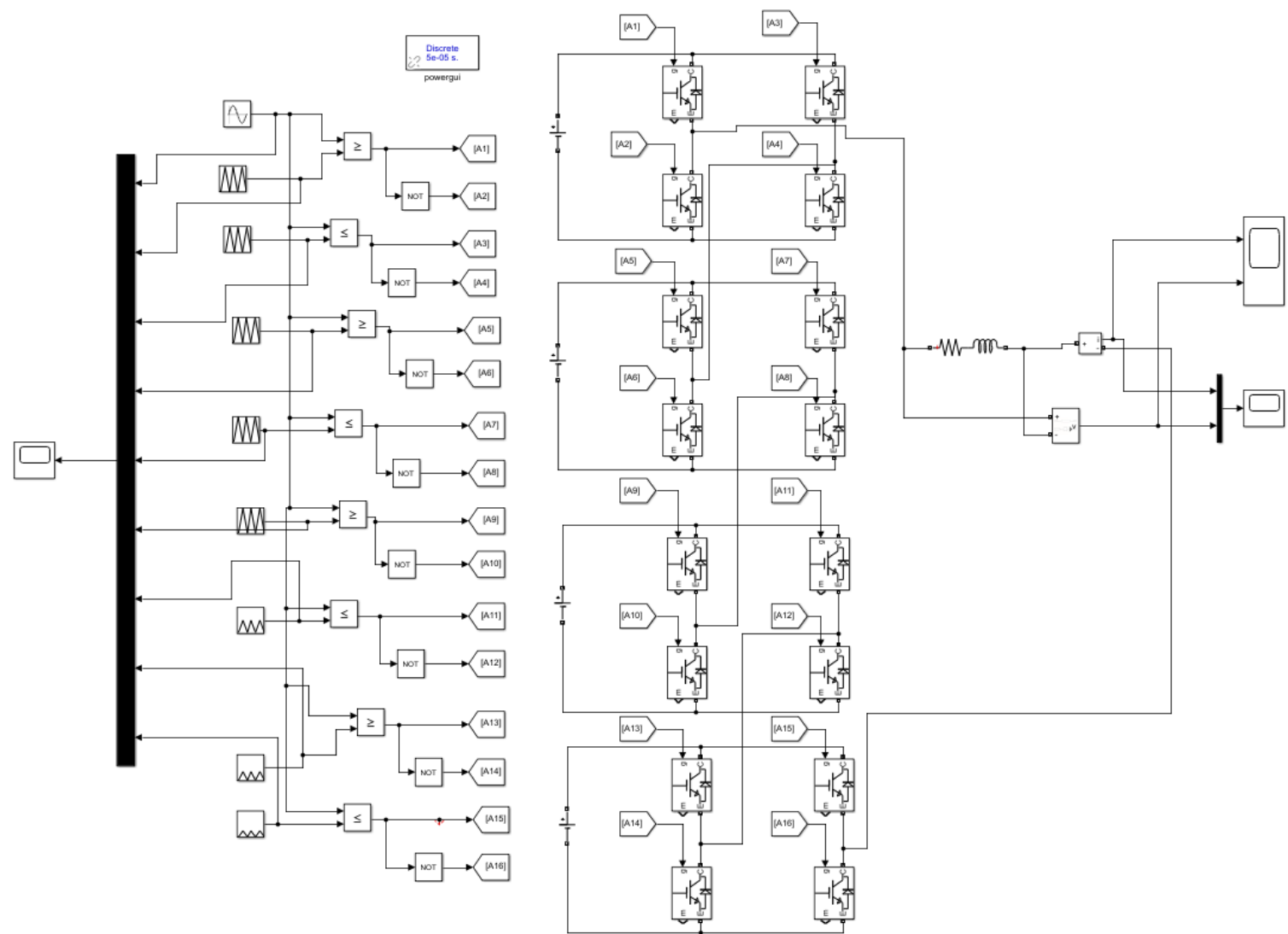

Figure 11. Matlab Simulink model for nine level inverter using SPWM

Eight equal levels of triangular waves with $f_{c}=1300 \mathrm{~Hz}$ are needed to cross the sinusoidal system frequency $f=50 \mathrm{~Hz}$ shown in Figure 12 and the triggering instants are defined. 


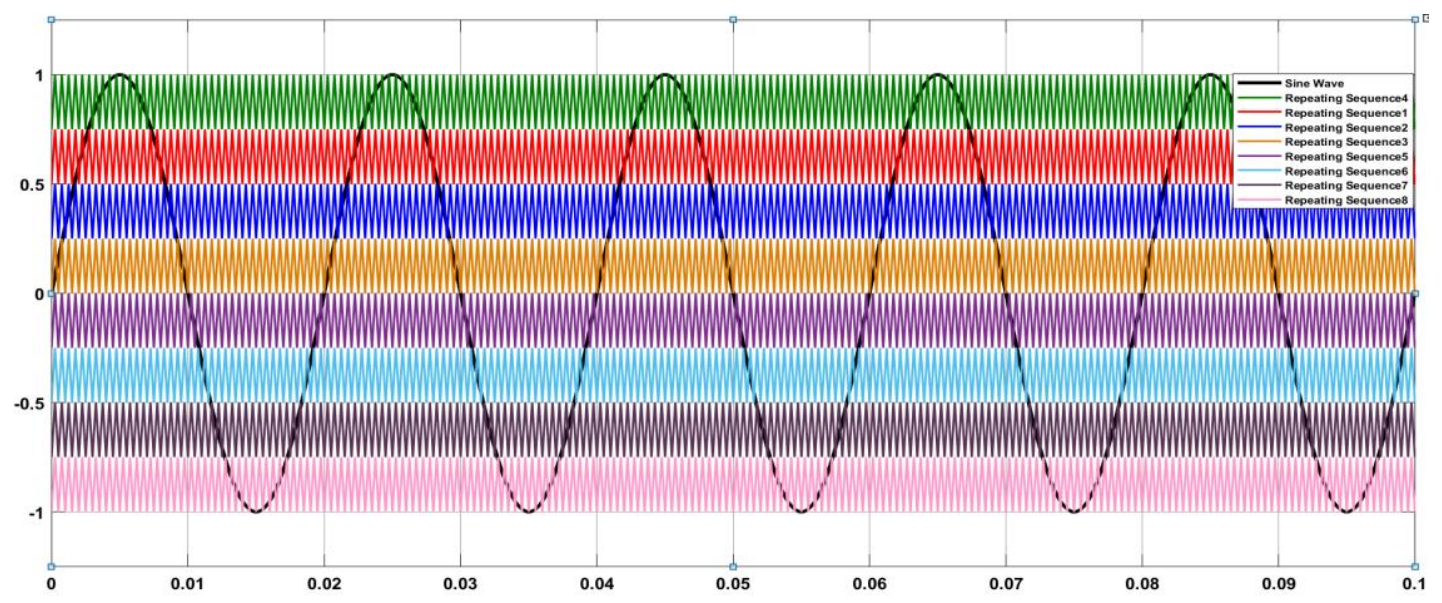

Figure 12. Sinusoidal pulse width modulation criteria for nine level inverter

The output voltage with its frequency spectrum is shown in Figure 13 and are almost similar to the output shown in Figure 10 for SHE technique. Due to high carrier frequency the number of triggering instants in SPWM are very large compared with the limited triggering instants in SHE approaches. This will increase the switching losses compared with SHE technique.

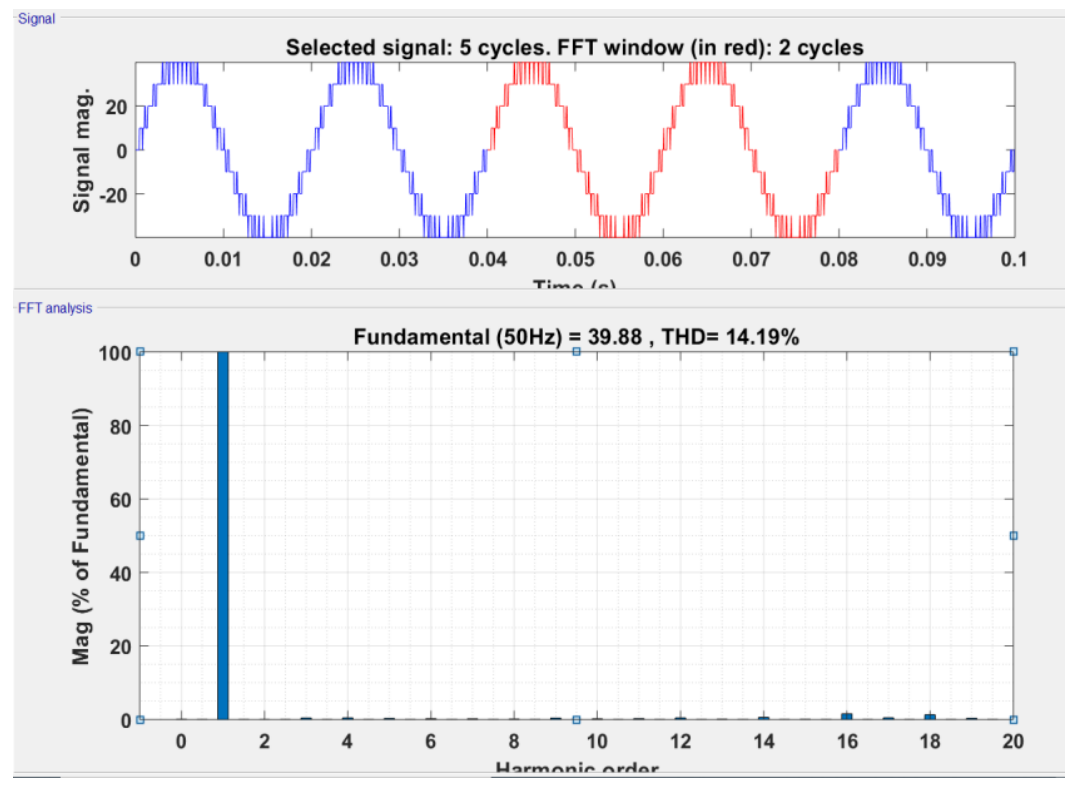

Figure 13. Simulink output voltage and frequency spectrum for nine level inverter using SPWM

This makes SHE technique the preferable method to be used in inverter applications. Recently many works were done to decrease number of switching devices in order to decrease the switching losses [4]. A modified Simulink model shown in Figure 14. To the centre of the left diode bridges a MOSFET transistor is added that will allow to change the path of the current in a sequence to eliminate some of switches needed in MLI. For example, to get 13 level MLI we need $6 \mathrm{H}$-bridges, but the mentioned topology reduces the number of H-bridges to three only with addition of three controlling MOSFETs transistors. This approach can be used in all previous topologies. The Simulink output current and voltage are shown in Figure 15 and the staircase of the thirteen levels are very smooth. 

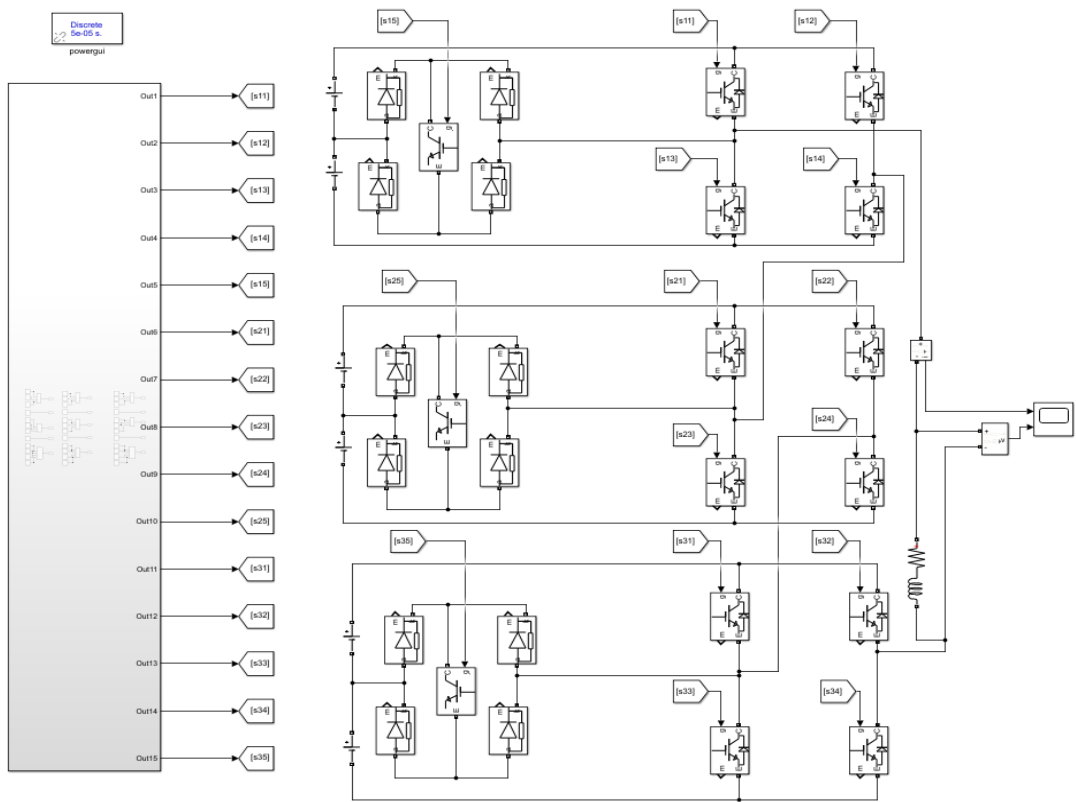

Figure 14. Modified Simulink model for eleven level inverter using SHE

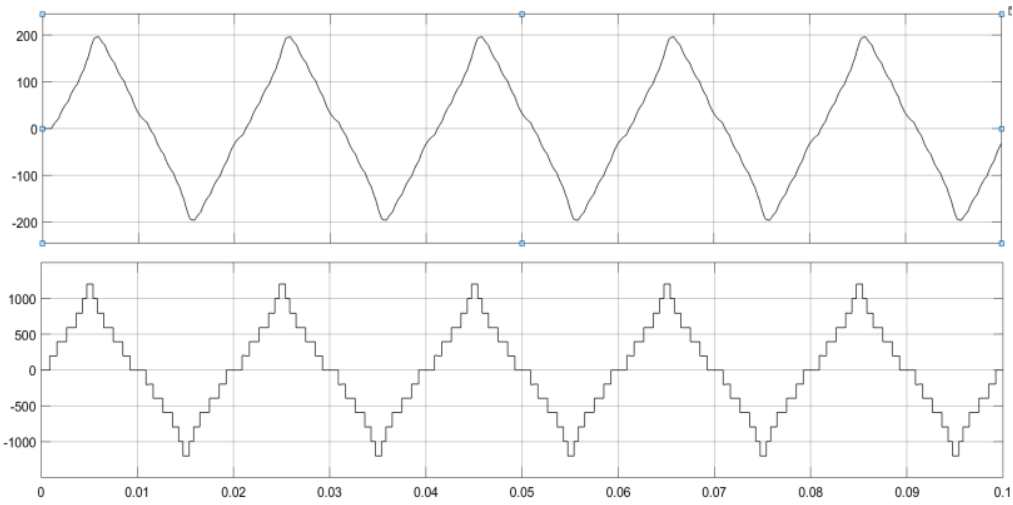

Figure 15. Simulink output current and voltage for thirteen levels MLI

\section{CONCLUSION}

Implementation of cascaded multilevel single-phase inverter using selective harmonic elimination approach shows reduced total harmonic distortion THD and few hard ware components compared with the traditional sinusoidal pulse width modulation SPWM. The implementation ensures any desired level ranges starting from five level inverter. The triggering instants for the operation of the MOSFETs switches are determined when solving the related nonlinear sinusoidal equations using the traditional Newton Raphson method. Arduino Mega 2560 microcontroller is used for the generation of the digital signals and injected to the gates of the MOSFETs. An optocoupler insulator is added between the inverter circuit and the microcontroller to ensure safety operation of both hardware's. The practical results show agreement with the Simulink model in Matlab software for the cases studied in this work. A Simulink for a recent modified multilevel inverter topology that reduces the number of the H-bridge is also shown for thirteen level inverter and it is suggested to be implemented in future work.

\section{REFERENCES}

[1] Joes Rodriguez, Samir Kouro, Ramon C. "Multilevel converter: enabling technology for high power application," Proceeding of the IEEE, vol. 97, no. 11, 2009.

[2] Jose Rodrguez. Jih-sheng lai and fang Zheng Peng, "Multilevel inverters: A survey of topologies, controls, and applications". IEEE Transactions on Industrial Electronics, vol. 49. no. 4, August 2002. 
[3] Najafi E Yatim, AHM, "Design and implementation of a new multilevel inverter topology," Industrial electronics IEEE Transactions, vol. 59, no. 2, pp. 4148-4154, 2012.

[4] Sung-Jum Park, Feel-Son Kange, "A new single phase five-level PWM inverter employing a deadbeat control scheme," IEEE Transaction on power electronics, vol. 18, no. 3, May 2003.

[5] M.Sujatha, A.K. Parvathy "Improved reliable multilevel inverter for renewable energy systems," Indonesian Journal of Electrical Engineering and Computer Science (IJEECS), vol. 14, no. 3, pp. 1141-1147, June 2019.

[6] M. D. Siddique, S. Mekhilef, N. M. Shah, A. Sarwar, A. Iqbal and M. A. Memon, "A New Multilevel Inverter Topology with Reduce Switch Count," in IEEE Access, vol. 7, pp. 58584-58594, 2019, doi: 10.1109/ACCESS.2019.2914430.

[7] Marif Daula, Saad Mekhileff, Noraisayah, Adil Sarwar e.t.l, "A new multilevel inverter topology with reduce switch count". IEEE Access, vol. 7, pp. 58584-58594, 2019.

[8] Muhammad H. Rashid, "Power Electronics, Devices, Circuits, and Applications," Fourth Edition, Pearson Education Limited 2014.

[9] Gerald. C. Diyolce, Candidw.U. Eya, "Modeling and simulation of five-phase induction motor fed with pulse modulated five-phase multilevel voltage source inverter topologies," Journal of Advances in Electrical Drives, vol. 4, no. 2, pp. 6-22, Mat Journals 2019.

[10] Ersoy Beser, Birol Arifouglu, Sabri Samur and Esra Kandemir Beser, "Design and application of a single-phase multilevel inverter suitable for using a s a voltage harmonic source," Journal pf power electronics, vol. 10, no. 2, pp.138-145, March 2010.

[11] Tapan Kumar Chakraborty, AshiqueAnan e.t.l. "Generation of 13-level output voltage from single-phase multilevel inverter consisting of cascaded three H-bridge units," 2nd IEEE International Conference on Power Electronics, Intelligent Control and Energy Systems (ICPEICES) 2018.

[12] Pouya Tarassodi, Alireza Siadatan, Milad Keshani, "Single-Phase Multi-Level Inverter Suitable for Symmetrical and Asymmetrical Photovoltaic (PV) Applications," IEEE 28th International Symposium on Industrial Electronics (ISIE), 2019

[13] M. M. Hasan, S. Mekhilef and M. Ahmed, "Three-phase hybrid multilevel inverter with less power electronic components using space vector modulation," in IET Power Electronics, vol. 7, no. 5, pp. 1256-1265, May 2014, doi: 10.1049/iet-pel.2013.0237.

[14] Masaoud, H. W. Ping, S. Mekhilef and A. Taallah, "Novel configuration for multilevel DC-link three-phase fivelevel inverter," in IET Power Electronics, vol. 7, no. 12, pp. 3052-3061, 12 2014, doi: 10.1049/iet-pel.2013.0812.

[15] N. Prabaharan and K. Palanisamy, "A comprehensive review on reduced switch multilevel inverter topologies, modulation techniques and applications," Renew. Sustain. Energy Rev., vol. 76, pp. 1248-1282, Sep. 2017.

[16] H. Akagi, "Multilevel converters: Fundamental circuits and systems," Proc. IEEE, vol. 105, no. 11, pp. 2048-2065, Nov. 2017.

[17] J. I. Leon, S. Vazquez, and L. G. Franquelo, "Multilevel converters: Control and modulation techniques for their operation and industrial applications," Proc. IEEE, vol. 105, no. 11, pp. 2066-2081, Nov. 2017.

[18] Ammar Masaoud, Hew Wooi Ping, Saad Mekhilef \& Hamza Omar Belkamel, "A New Five-level Single-phase Inverter Employing a Space Vector Current Control," Electric Power Components and Systems, vol. 42, no. 11, pp. 1121-1130, 2014, DOI: 10.1080/15325008.2014.921946.

[19] Mekhilef, Saad; Kadir, Mohamad N. Abdul "Voltage Control of Three-Stage Hybrid Multilevel Inverter Using Vector Transformation", IEEE Transactions on Power Electronics, vol. 25, no. 10, pp. 2599-2606, 2010.

[20] S. Mekhilef and M. N. Abdul Kadir, "Novel Vector Control Method for Three-Stage Hybrid Cascaded Multilevel Inverter," in IEEE Transactions on Industrial Electronics, vol. 58, no. 4, pp. 1339-1349, April 2011, doi: 10.1109/TIE.2010.2049716.

[21] M. D. Siddique et al., "Low Switching Frequency Based Asymmetrical Multilevel Inverter Topology with Reduced Switch Count," in IEEE Access, vol. 7, pp. 86374-86383, 2019, doi: 10.1109/ACCESS.2019.2925277.

[22] M. D. Siddique, S. Mekhilef, N. M. Shah, A. Sarwar, A. Iqbal and M. A. Memon, "A New Multilevel Inverter Topology with Reduce Switch Count," in IEEE Access, vol. 7, pp. 58584-58594, 2019, doi: 10.1109/ACCESS.2019.2914430.

[23] N. Prabaharan and K. Palanisamy, "A comprehensive review on reduced switch multilevel inverter topologies, modulation techniques and applications," Renew. Sustain. Energy Rev., vol. 76, pp. 1248-1282, Sep. 2017.

[24] G. Konstantinou, J. Pou, S. Ceballos, R. Darus, and V. G. Agelidis, "Switching frequency analysis of staircasemodulated modular multilevel converters and equivalent PWM techniques," IEEE Trans. Power Del., vol. 31, no. 1, pp. 28-36, Feb. 2016.

[25] K. K. Gupta, A. Ranjan, P. Bhatnagar, L. K. Sahu, and S. Jain, "Multilevel inverter topologies with reduced device count: A review," IEEE Trans. Power Electron., vol. 31, no. 1, pp. 135-151, Jan. 2016.

[26] F. Z. Dekhandji, et. al., "Harmonic Reduction and Elimination in Three Phase PWM Inverters using a SpiralInspired Optimization Technique," Algerian Journal of Environmental Science and Technology, vol. 6, no. 3, 2020.

[27] Yasmina Azzougui and Abdelmadjid Recioui, "Application of the moth flame optimisation to the selective harmonic elimination in multilevel converters," Int. J. Smart Grid and Green Communications, Inderscience, vol. 2 , no. 1 , pp. $1-18,2020$ 